Article

\title{
Fatty Acid Based Microemulsions to Combat Ophthalmia Neonatorum Caused by Neisseria gonorrhoeae and Staphylococcus aureus
}

\author{
Ummara Butt ${ }^{1}$, Amr ElShaer ${ }^{1, *}$, Lori A. S. Snyder ${ }^{2}{ }^{(1)}$, Ali A. Al-Kinani ${ }^{1}{ }^{(\mathbb{D})}$, Adam Le Gresley ${ }^{1}$ \\ and Raid G. Alany ${ }^{1,3}$ \\ 1 Drug Discovery, Delivery and Patient Care (DDDPC), School of Life Sciences, Pharmacy and Chemistry, \\ Kingston University, Penrhyn Road, Kingston upon Thames, Surrey KT1 2EE, UK; \\ k1266883@kingston.ac.uk (U.B.); A.Alkinani@kingston.ac.uk (A.A.A.-K.); \\ A.Legresley@kingston.ac.uk (A.L.G.); R.Alany@kingston.ac.uk (R.G.A.) \\ 2 School of Life Sciences, Pharmacy and Chemistry, Kingston University, Kingston upon Thames KT1 2EE, UK; \\ L.Snyder@kingston.ac.uk \\ 3 School of Pharmacy, University of Auckland, Auckland 1142, New Zealand \\ * Correspondence: a.elshaer@kingston.ac.uk; Tel.: +44-0-20-8417-7416
}

Received: 29 November 2017; Accepted: 8 January 2018; Published: 19 January 2018

\begin{abstract}
The bacterial species Neisseria gonorrhoeae (N. gonorrhoeae) and Staphylococcus aureus (S. aureus) are amongst the main microorganisms that cause ophthalmia neonatorum. The current treatment involves the use of various antibiotics such as ciprofloxacin, cephalosporin, ceftriaxone and cefotaxime. However, this treatment strategy is becoming more ineffective due to the antibiotic resistance in N. gonorrhoeae. The current study explores the potential use of fatty acid based microemulsions (ME) to prevent $N$. gonorrhoeae and S. aureus infections in new-borns' eyes without harmful side effects such as corneal or conjunctiva irritation. Pseudo-ternary phase diagrams were constructed to evaluate microemulsion regions and six different $\alpha$-linolenic acid based microemulsions were prepared. The prepared formulations were characterized for $\alpha$-linolenic acid content, size, transparency, zeta potential, Polarized light Microscopy, antimicrobial activity and ex vivo ocular toxicity. The mean droplet size of the ME formulations was in the range of 190.4 to $350.5 \mathrm{~nm}$ and polydispersity index (PDI) values were in the range of 0.102 to 0.561 . All formulations were found stable upon storage for at least 8 weeks. In addition, self-diffusion coefficients determined by nuclear magnetic resonance (NMR) reflected that the diffusability of water increased at higher than $30 \% w / w$ water, while that of fatty acids and surfactants was in reverse. The antimicrobial efficacy of microemulsions was determined against $N$. gonorrhoeae and S. aureus. It was concluded that all microemulsions have strong antimicrobial effects against $N$. gonorrhoeae and S. aureus. Finally, bovine corneal opacity permeability (BCOP) and hen's egg chorioallantoic (HET-CAM) tests results showed that all microemulsion formulations were not strong ocular irritants.
\end{abstract}

Keywords: fatty acid; ophthalmia neonatorum; microemulsion; pseudo-ternary phase diagram; ocular toxicity/irritation potential

\section{Introduction}

Ophthalmia neonatorum is a form of conjunctivitis in new-borns, usually contracted during birth from passage through the infected birth canal of the mother [1]. The bacterial species Neisseria gonorrhoeae is the cause of the sexually transmitted disease gonorrhoea [2] and the cause of ophthalmia neonatorum. Neisseria gonorrhoeae ( $N$. gonorrhoeae) accounts for $30 \%$ to $45 \%$ of ophthalmia cases [3,4]. Nonsexually transmitted bacteria, such as Staphylococcus aureus (S. aureus), can also cause 
neonatal conjunctivitis. S. aureus accounts for $30 \%$ to $50 \%$ cases of ophthalmia neonatorum $[3,4]$. $N$. gonorrhoeae infection is of particular concern as it cannot be successfully treated, it can cause corneal ulceration and perforation of the globe of the eye, which can rapidly lead to blindness. If left untreated, the neonatal bacterial eye infections can potentially spread, causing life threatening conditions such as septicaemia and meningitis. Opthalmia neonatorum occurs in 1\% to $12 \%$ of new-born infants and leads to blindness in approximately 10,000 babies annually worldwide [5].

There are a variety of treatments that can be used against gonococcal ophthalmia neonatorum (GCON). Control strategies include the treatment of gonococcal infection in pregnant women, diagnosis and treatment of GCON and eye prophylaxis in the new born at birth. The treatment of gonococcal infections in pregnant women requires screening and is expensive [5]. Eye prophylaxis by the instillation of $1 \%$ silver nitrate in the first $h$ of life is not always possible and no longer in use as silver nitrate is toxic and causes chemical conjunctivitis [6,7]. Recently, various antibiotics such as ceftriaxone IV or IM and cefotaxime IM are recommended as first line therapy for gonococcal ophthalmia neonatorum and other gonococcal infections in the new born [8,9]. However, in the last few years, mutants of gonococci expressing significant resistance to these antibiotics have been identified worldwide [10,11].

It has been proposed that a fatty acid based eye formulation can be used as an alternative control strategy [8]. Several fatty acids have a broad spectrum of microbicidal activity against enveloped viruses and various Gram positive and Gram negative bacteria, including N. gonorrhoeae and $S$. aureus $[8,12]$. In recent years, microbicidal effects of medium- and long-chain fatty acids and their corresponding 1-monoglycerides have been studied. They have been found to have a broad spectrum of microbicidal activity against enveloped viruses and various bacteria in vitro, including pathogens such as herpes simplex virus (HSV), Neisseria gonorrhoea and Chlamydia trachomati [8,12].

Nearly 10 years ago, the bactericidal potencies of saturated and unsaturated fatty acids and monoglycerides (MGs) against Helicobacter pylori were determined following short incubations with freshly harvested cells over a range of $\mathrm{pHs}$. Lauric acid was found to kill the bacterial species at a minimum bactericidal concentration (MBC) of $1 \mathrm{mM}$ at $\mathrm{pH} 7.4$, myristoleic and linolenic acid were found to be potent at $\mathrm{MBC}$ of $0.5 \mathrm{mM}$ at $\mathrm{pH} 7.4$ and monolaurin was found to be the most potent monoglyceride (MBC $0.5 \mathrm{mM}$ ). The bactericidal potencies of unsaturated fatty acids were found to increase with degree of unsaturation [13]. It has been found that $N$. gonorrhoeae is highly susceptible to lauric acid (C12:0), myristic acid (C14:0), oleic acid (C18:1), linoleic acid (C18:2), linolenic acid (C18:3) and arachidonic acid (C20:4) but is resistant to straight-chain, saturated fatty acids with 18 or more carbons [14]. Various long-chain polyunsaturated fatty acids (LC-PUFAs)-including eicosapentaenoic acid (EPA; C20:5n-3), docosahexaenoic acid (DHA; C22:6n-3), $\gamma$-linolenic acid (GLA; C18:3n-6) and dihomo- $\gamma$-linolenic acid (DGLA; C20:3n-6) - have shown to exert highly potent activity against $S$. aureus [15]. In 1990, Bergsson et al. tested several fatty acids and their 1-monoglycerides for their microbicidal activities against $N$. gonorrhoea at a short inactivation time of $1 \mathrm{~min}$. It was shown that 1 min exposure to $2.5 \mathrm{mM}$ lauric acid and monocaprin-a monoglyceride of capric acid-causes the fastest and most effective killing of all strains of $N$. gonorrhoea tested [8]. Over ten years ago, a hydrogel containing $10 \mathrm{mM}$ monocaprin was found to kill high titres of $N$. gonorrhoea within 1 minute [16]. Although many studies looked at the microbial effects of fatty acids on various microbes, no studies evaluated the effect of fatty acid formulations on bacteria, fungi or viruses.

In the present study, a fatty acid based microemulsions were prepared. $\alpha$-linolenic acid was selected because of its significant antimicrobial activity against $N$. gonorrhoeae and S. aureus as per our previous studies [17,18]. The prepared microemulsions (ME) formulations were characterized by polarized light microscopy and self-diffusion NMR (Nuclear magnetic resonance). Different pharmaceutical formulation properties such as clarity, $\mathrm{pH}$, particle size, viscosity, physical and chemical stability and sterility of the formulations were investigated as part of the development phase of an eye formulation. In addition, antibacterial activity of the $\alpha$-linolenic acid-based ME was tested against N. gonorrhoeae and S. aureus. Finally, the eye formulations were tested for ocular 
toxicity/irritation potential using the bovine corneal opacity and permeability (BCOP) test and the hens egg chorioallantoic membrane test (HET-CAM). The estimated costs for routine neonatal ocular prophylaxis are $\$ 7.7$ per child and $\$ 1.94$ for treatment using erythromycin. Nonetheless the costs will increase with the development of resistance to the current antibiotics used for treatment of ophthalmia neonatorum conditions. The use of fatty acids can minimize the costs associated with the antimicrobial resistance [19].

\section{Results and Discussion}

\subsection{Saturation Solubility}

Absorbance was measured by UV spectrophotometer at $350 \mathrm{~nm}$ to determine the solubility of $\alpha$-linolenic acid in various surfactants. The correlation between concentration $(\mathrm{mg} / \mathrm{mL})$ and absorbance (average of 3 determinations) was plotted to find out saturation point of a compound. It was found that all excipients were able to dissolve $\alpha$-linolenic acid, although not to the same extent.

Solubility of $\alpha$-linolenic acid in different excipients is summarized in Figure $1 \mathrm{~A}$. The results of saturation solubility studies revealed that $\alpha$-linolenic acid has high solubility in Cremophor EL and Tween 80 as compared to Tween 20, Labrasol, Labrafil M2125 and Caproyl 90. Amongst the tested co-surfactants, Transcutol P and PEG 400 solubilized $\alpha$-linolenic acid the most. Therefore, Tween 80 and Cremophor EL were selected as surfactants and Transcutol P and PEG 400 were selected as cosurfactants, respectively, for the phase behaviour study.

A

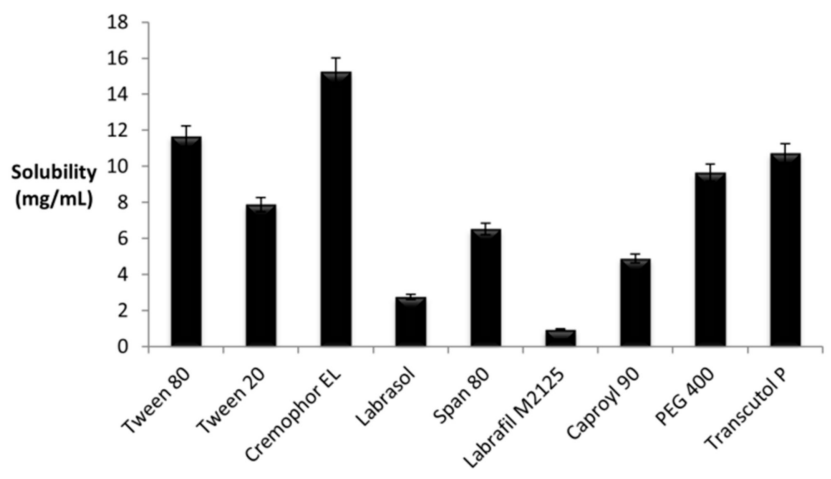

B

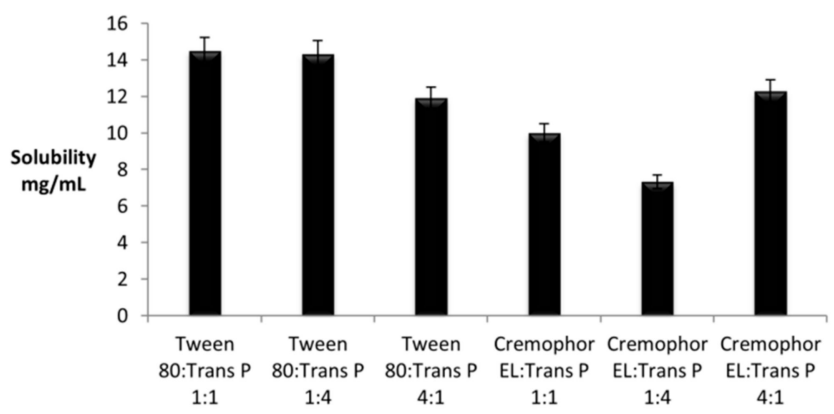

Figure 1. Saturation solubility of $\alpha$-linolenic acid in different surfactant (A) and different ratios of surfactants blends (B). Mean $\pm \mathrm{SD}, n=3$.

The solubility profile of $\alpha$-linolenic acid in the selected surfactant/co-surfactant blends as shown in Figure $1 \mathrm{~B}$ reveals that $\alpha$-linolenic acid had the highest solubility in Tween $80 /$ Transcutol P mixture compared with Cremophor EL/Transcutol P.

The high solubility of $\alpha$-linolenic acid in Tween 80 and Cremophor EL could be due to the structural similarities between $\alpha$-linolenic acid, Tween 80 and Cremophor EL. $\alpha$-linolenic acid is a long chain (C18) of unsaturated fatty acid. Tween 80 is structurally composed of polyoxyethylene sorbitan 
(head group) and unsaturated oleic acid (tail group). Tween 80 shares a carbon chain tail of similar length (C18) to $\alpha$-linolenic acid.

Cremophor EL head portion consists of polyethylene glycols and glycerol ethoxylates, whereas the tail portion is composed of oxyethylated triglycerides of a long chain (C18) unsaturated ricinoleic acid, which is structurally similar to the long chain (C18) of unsaturated $\alpha$-linolenic acid.

Both Tween 80 and Cremophor EL have a hydrophobic tail of similar length (C18) to $\alpha$-linolenic acid. It is possible that these hydrophobic chains were responsible for increasing the solubility profile for $\alpha$-linolenic acid. Both Tween 80 (Hydrophilic-Lipophilic Balance; HLB $=15$ ) and Cremophor EL (HLB = 14) have high hydrophilic nature and good emulsion forming capacity due to their high HLB values. However, $\alpha$-linolenic acid solubility was higher in Cremphor EL as compared to Tween 80 . This could be because Tween 80 consists of a single chain of oleic acid as lipophilic part while Cremophore EL has three fatty acid chains attached to PEG-glycerol. This bulkier lipophilic part enhances the emulsification properties of Cremophore EL [20]. Nonetheless, Tween 20 (HLB = 16.7) showed low solubility capacity despite having high HLB value. This could be due the different hydrophobic tail group, which is composed of saturated medium-chain lauric acid (C12). These results are in agreement with the results of the previous study conducted by Mosca et al. [21] and show that the length and size of the hydrophobic side chains of surfactants determines the interactions with the oil phase [21]. Labrasol (HLB = 12), labrafil M2125 (HLB =4) and Caproyl 90 (HLB =6) showed the lowest solubility enhancement for $\alpha$-linolenic. This might be due to their low HLB values that cause incompatibility between these hydrophilic surfactants and $\alpha$-linolenic acid.

Based on saturation solubility studies, Transcutol P was selected as co-surfactant because $\alpha$-linolenic acid showed good solubility in this solvent. A blend of surfactants and co-surfactant is needed to increase drug solubility and to obtain a stable microemulsion [22]. These co-surfactants help to further reduce the surface tension and fluidize the surfactant film, which increases the entropy of the system leading to its thermodynamic stability. Co-surfactants also increase the flexibility of the interfacial film around the microemulsion droplet [23,24].

It is known that a single surfactant is not sufficient to form balanced microemulsions and a combination of surfactant and co-surfactant is required to optimize the formation of a microemulsion [25]. Therefore, the selection of surfactant/co-surfactant blends is important in the formulation of a stable dispersion system.

The selected surfactants were blended with the selected co-surfactant in ratios of 1:1, 1:4 and 4:1 (w/w). Among the surfactant/co-surfactant blends, two mixtures had the highest solubilisation capacities for $\alpha$-linolenic acid: Tween 80/Transcutol P 1:1 (w/w) and Cremophor EL/Transcutol P 4:1 $(w / w)$. Thus, these two blends were selected to study the phase behaviour of $\alpha$-linolenic acid.

\subsection{Construction of Pseudo-Ternary Phase Diagrams}

The pseudo-ternary phase diagrams were constructed using phase diagram by micro-plate dilution (PDMPD) method. Ternary phase diagrams were constructed by taking 1:1 ratio of Tween 80/Transcutol P and 4:1 ratio of Cremophor EL/Transcutol P. The shaded area of the phase diagrams shows the ME region, whereas the non-shaded area displays the none ME region. The pseudo-ternary phase diagrams of the $\alpha$-linolenic acid/surfactant:co-surfactant/water are shown in Figure 2. The phase behaviour study revealed that the emulsion region was larger with 1:1 Tween 80/Transcutol P (Figure 2A) in comparison with Cremophor EL/Transcutol P (Figure 2B). From the phase diagrams, it can be observed that ME regions increase with increasing surfactant:co-surfactant mix ratio. This could be due to the effect of the hydrophilic co-solvents and/or co-surfactants that reduce the interfacial tension and increase the fluidity of the oil-water interface and hence, promoted the formation of microemulsions [23,24]. 
A

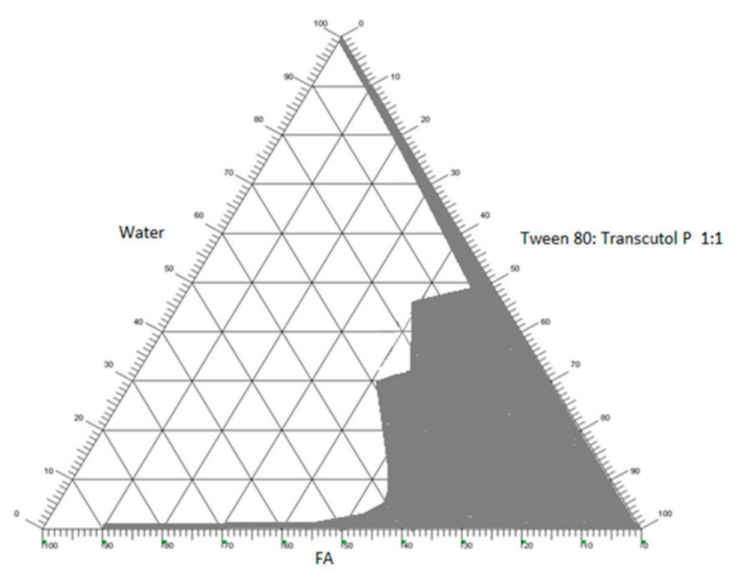

B

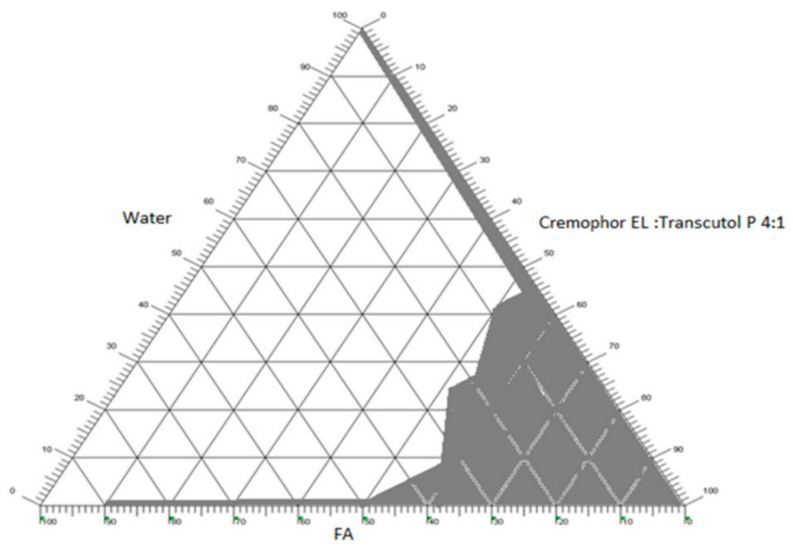

Figure 2. Pseudo-ternary phase diagrams of $\alpha$-linolenic acid, water, surfactant/cosurfactant $(\mathrm{S} / \mathrm{CoS})$ mix made of (A) Tween 80/Transcutol P (1:1), (B) Cremophor EL/Transcutol P (4:1).

\subsection{Preparation and Characterization of Microemulsions}

Formulations were developed based on the microemulsion zone of pseudo-ternary phase diagrams. The composition of selected ME formulations is given in Table 1. All the developed formulations were found to be clear/transparent on visual inspection. The clarity of microemulsions was also checked by transparency, measured as percent transmittance (\%T). All ME formulations showed \% transmittance value greater than $98 \%$ (Table 1 ). These results indicate $t$ that these compositions are isotropic one-phase systems. 
Table 1. Composition and characterisation criteria of the selected microemulsion formulations, fatty acid microemulsions were characterised for their particle size $(\mathrm{nm})$, zeta potential $(\mathrm{mV})$, light transmittance $(\%)$, viscosity $(\mathrm{mPa} \cdot \mathrm{S})$ and contact angle $(\theta)$. Data is presented as mean \pm standard deviation $(\mathrm{SD})$, where $n=3$.

\begin{tabular}{|c|c|c|c|c|c|c|c|c|c|c|c|c|}
\hline \multirow[b]{2}{*}{ Formulation } & \multicolumn{3}{|c|}{ Composition } & \multirow{2}{*}{$\begin{array}{c}\text { Particle Size } \\
\pm \mathrm{SD}(\mathrm{nm})\end{array}$} & \multirow[b]{2}{*}{$\mathrm{PDI} \pm \mathrm{SD}$} & \multirow{2}{*}{$\begin{array}{c}\text { Zeta } \\
\text { Potential } \\
(\mathrm{mV})\end{array}$} & \multirow{2}{*}{$\begin{array}{c}\% \\
\text { Transmittance } \\
\text { (at } 600 \mathrm{~nm} \text { ) }\end{array}$} & \multirow[b]{2}{*}{$\mathrm{pH}$} & \multirow{2}{*}{$\begin{array}{l}\text { Viscosity } \\
\text { (mPa.S) }\end{array}$} & \multirow{2}{*}{$\begin{array}{c}\alpha \text {-Linolenic } \\
\text { Acid } \\
\text { Content } \\
\% \\
\end{array}$} & \multirow{2}{*}{$\begin{array}{c}\text { Contact } \\
\text { Angle on } \\
\text { Hydrophilic } \\
\text { Surface }\left({ }^{\circ}\right)\end{array}$} & \multirow{2}{*}{$\begin{array}{c}\text { Contact } \\
\text { Angle on } \\
\text { Hydrophobi } \\
\text { Surface }\left({ }^{\circ}\right)\end{array}$} \\
\hline & $\begin{array}{l}\text { Fatty Acid } \\
\text { (FA) } \%\end{array}$ & $\mathrm{~S} / \mathrm{CoS} \%$ & Water\% & & & & & & & & & \\
\hline T1 (Tween80/Transcutol P) & 4 & 88 & 8 & $190.4 \pm 2.3$ & $0.309 \pm 0.12$ & $0.124 \pm 0.022$ & $98 \%$ & $5.96 \pm 0.02$ & $65.32 \pm 2.15$ & 92.5 & $14.1 \pm 0.85$ & $29.5 \pm 2.43$ \\
\hline T2 (Tween8/Transcutol P) & 6 & 60 & 34 & $205.1 \pm 1.2$ & $0.551 \pm 0.085$ & $0.107 \pm 0.014$ & $98 \%$ & $4.66 \pm 0.01$ & $96.12 \pm 4.22$ & 95.9 & $12.2 \pm 0.06$ & $35.2 \pm 3.73$ \\
\hline T3 (Tween8/Transcutol P) & 35 & 60 & 5 & $219.1 \pm 1.5$ & $0.383 \pm 0.056$ & $0.394 \pm 0.035$ & $115 \%$ & $5.33 \pm 0.02$ & $56.67 \pm 2.32$ & 99.8 & $15.7 \pm 2.51$ & $25.9 \pm 3.70$ \\
\hline $\begin{array}{l}\text { C1 (Cremophor } \\
\text { EL/Transcutol P) }\end{array}$ & 4 & 86 & 10 & $1 \pm 1.9$ & $0.561 \pm 0.032$ & $0.025 \pm 0.011$ & $99 \%$ & $6.23 \pm 0.02$ & $82.53 \pm 1.63$ & 91.8 & $25.1 \pm 2.41$ & $34.8 \pm 3.08$ \\
\hline $\begin{array}{c}\text { C2 (Cremophor } \\
\text { EL/Transcutol P) }\end{array}$ & 6 & 62 & 32 & $225.6 \pm 2.1$ & $0.392 \pm 0.14$ & $0.303 \pm 0.054$ & $98 \%$ & $5.43 \pm 0.01$ & $\begin{array}{c}101.42 \pm \\
3.11\end{array}$ & 93.3 & $16.2 \pm 3.36$ & $43.8 \pm 4.30$ \\
\hline
\end{tabular}




\subsubsection{Characterization of Microemulsions}

Polarized light microscopy can distinguish between isotropic and anisotropic materials. The ME samples containing water/surfactant:co-surfactant/oil were examined under polarized light for sample anisotropy and birefringence. The binary systems containing only water/surfactant were also observed under polarized light. The ME samples did not show any birefringence and appeared completely dark under polarized light (Figure 3C) characteristic of isotropic material. On the other hand, textures characteristic of lyotropic lamellar liquid crystals (were seen with water/surfactant micrographs as shown in Figure 3A,B. These observations indicate that all the ME formulations were optically isotropic colloidal dispersions.
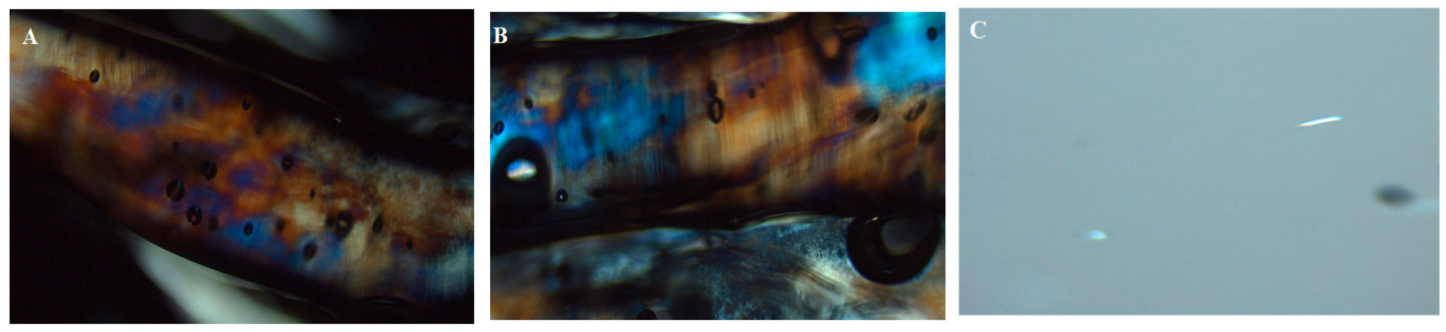

Figure 3. Photomicrographs of samples under polarized light microscopy (A) Lamellar liquid crystals of Tween 80/water, (B) Lamellar liquid crystals of Cremophor EL/water, (C) Microemulsion.

The droplet size plays a significant role in the microemulsion stability and performance because it determines the rate and extent of drug release as well as in vivo absorption. It has been reported that the smaller droplet size of the emulsion provides better drug absorption by increasing the interfacial area in contact with biological membranes [26,27]. Table 1 shows the results of particle size analysis, polydispersity index (PDI) and zeta potential of prepared microemulsions. All ME formulations showed an average droplet size of more than $200 \mathrm{~nm}$ except T1 which showed the smallest droplet size of $190.4 \pm 2.31 \mathrm{~nm}$. The overall higher droplet size could be due to the fact that both surfactants used in ME formulations, Tween 80 and Cremophor EL, have alkyl carbon chain lengths of 18, which is similar to the long chain (C18) of unsaturated $\alpha$-linolenic acid (oil). This finding was consistent with a previous study which reported that oil with carbon chain length similar to that of surfactant increases the average droplet size [28-30]. The PDI value for all formulations was less than 1 which is desirable (Table 1). The lower PDI value indicates a higher uniformity of the droplet size in the formulation [31]. Zeta potential is related to the stability of colloidal dispersions. Zeta potential indicates the degree of repulsion between adjacent, similarly charged particles in dispersion. When the zeta potential value is high, the electrostatic repulsive forces between the droplets increase which prevents the coalescence of the droplets. So, colloids with high zeta potential (negative or positive) are electrically stabilized [32,33]. The mean zeta potential value of the prepared microemulsions was consistently negative and ranged between $-0.025 \pm 0.011$ and $-0.394 \pm 0.035 \mathrm{mV}$, which was generally of smaller magnitude (Table 1). These low zeta potential values could be due to the larger droplet sizes. The use of non-ionic surfactants, Tween 80 and Cremophor EL also lowers the zeta potential values [34]. Negative zeta potential measurements indicate that the interface is negatively charged. This negative charge imparts stability to the ME system by producing electrostatic repulsive forces of head groups which thereby hindering aggregation with nearby droplets [35].

The $\mathrm{pH}$ values of all ME formulations are given in Table 1. The $\mathrm{pH}$ of all ME formulation ranged between 4.66 and 6.23 , which is within the normal $\mathrm{pH}$ range of marketed ophthalmic solutions. The normal $\mathrm{pH}$ value is one of the formulation considerations that may help reducing the eye irritation produced upon instillation.

All microemulsion samples were found to have viscosities in the range of 56 to $101 \mathrm{mPa} \cdot \mathrm{S}$. Table 1 gives the viscosity measurements for all ME formulations. These results indicate that 
formulation C2 showed the highest viscosity. It was observed that there was an increase in viscosity with an increase in the water content and surfactant:co-surfactant ratio.

The drug content in the ME formulations was measured using the previously published Gas-chromatography (GC) method [17]. The percent drug content of all ME formulations is shown in Table 1. The amount of the FA in all ME formulations ranged from $92 \%$ to $99 \%$ of the original amount which indicates that the FA is stable when loaded into these ME systems.

To evaluate the stability of the selected ME formulations, they were kept at different temperatures $\left(4{ }^{\circ} \mathrm{C}, 25^{\circ} \mathrm{C}\right.$ and $\left.40{ }^{\circ} \mathrm{C}\right)$ for 8 weeks and were evaluated periodically. Results of stability studies indicated that after 8 weeks, there were no significant changes ( $p$ value $>0.05$ ) in the initial droplet size and drug content of the microemulsions stored at $4{ }^{\circ} \mathrm{C}$ and $25{ }^{\circ} \mathrm{C}$ and there were no sign of phase separation or drug precipitation on storage. However, slight changes were observed in the initial droplet size and drug content of the microemulsions stored at $40{ }^{\circ} \mathrm{C}$. This might be due to the oxidative degradation of the linolenic acid in the MEs at higher temperatures as suggested earlier by [36]. The results are shown in Figures 4 and 5. Earlier reports [37] suggested the autoxidation of linolenic acid into hydroperoxides at carbon 9, 12, 13 and 16. Also secondary oxidation products such as propanal, 2-butenal and 2-pentenal were reported. The relative autoxidation rate of linolenic acid ranges between 1:40 and 50:100 according to the oxygen update [37]. According the current results it is evident that the stability of linolenic acid in the microemulsion formulations is high. Possibly the ME formulations reduced the oxygen contact with the fatty acid, hence protected the FA from degradation caused by autoxidation.
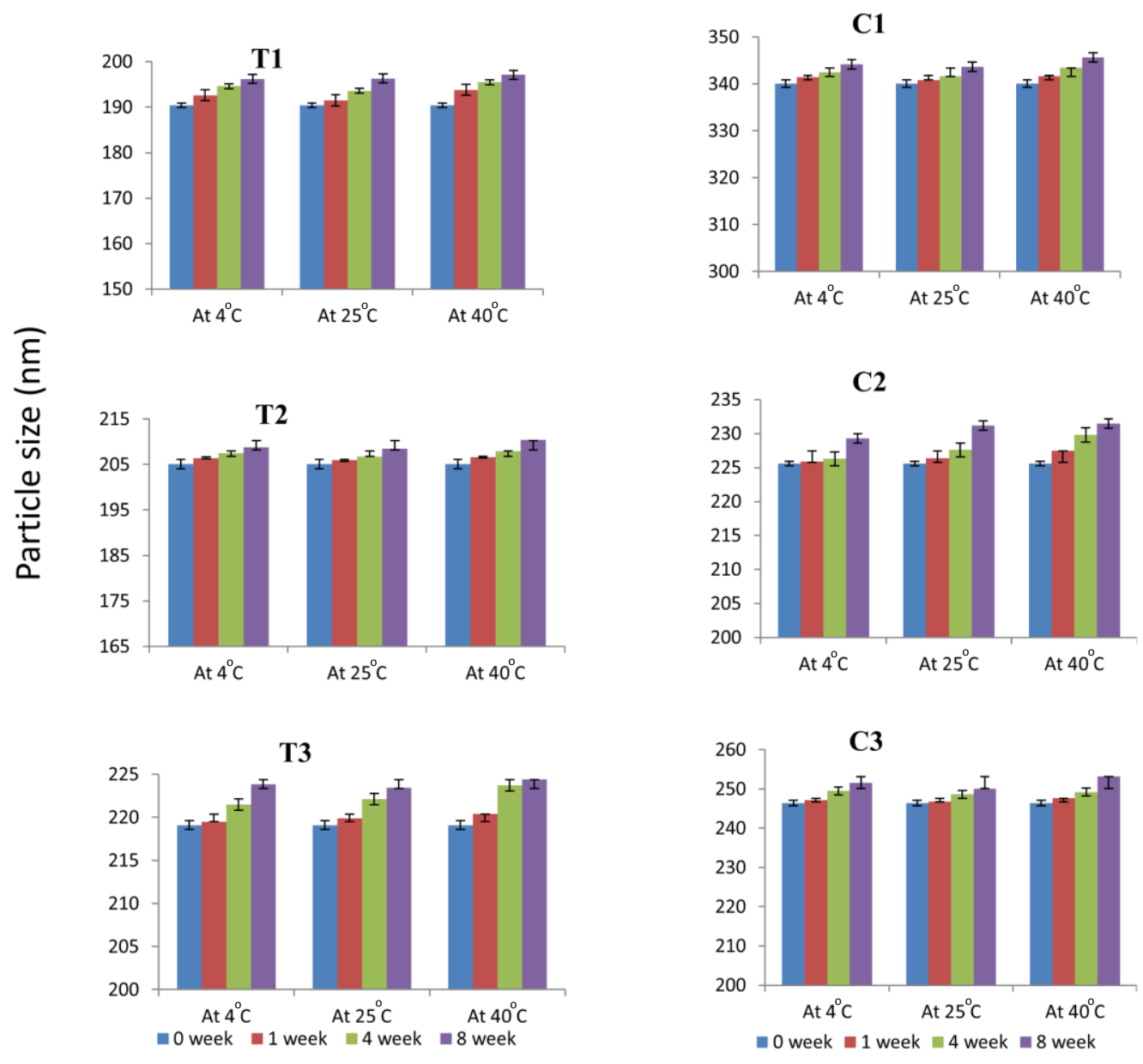

Figure 4. Particle size of microemulsion formulations at 0,1 week, 4 weeks and 8 weeks interval at $4{ }^{\circ} \mathrm{C}, 25^{\circ} \mathrm{C}$ and $40{ }^{\circ} \mathrm{C}$. Mean $\pm \mathrm{SD}, n=3$. 

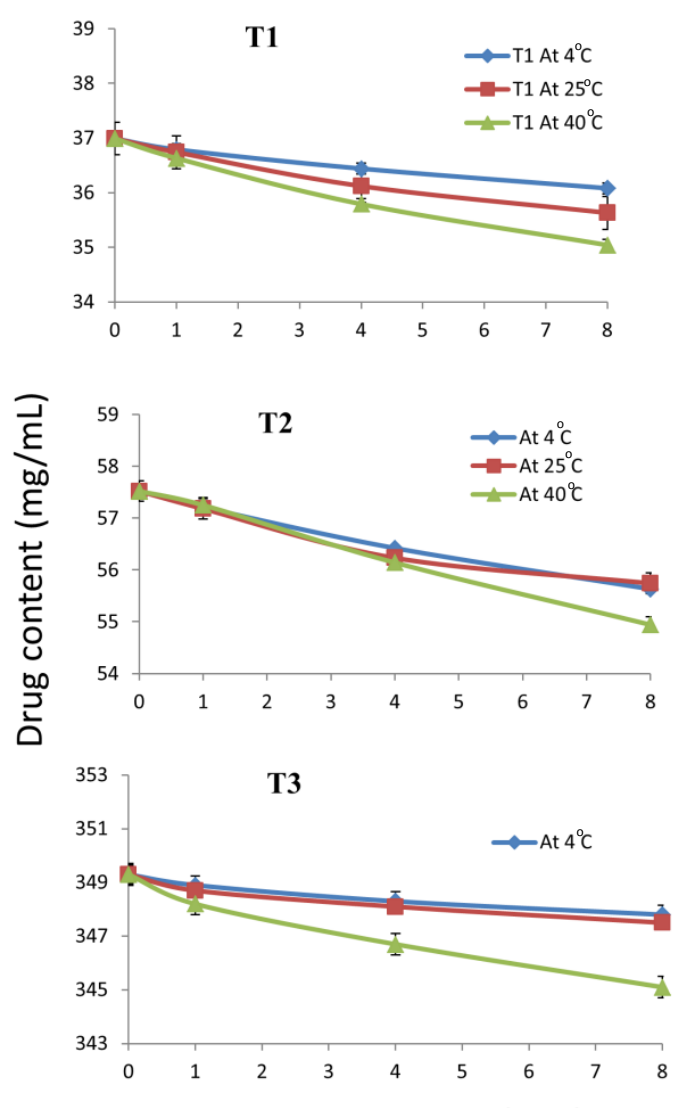
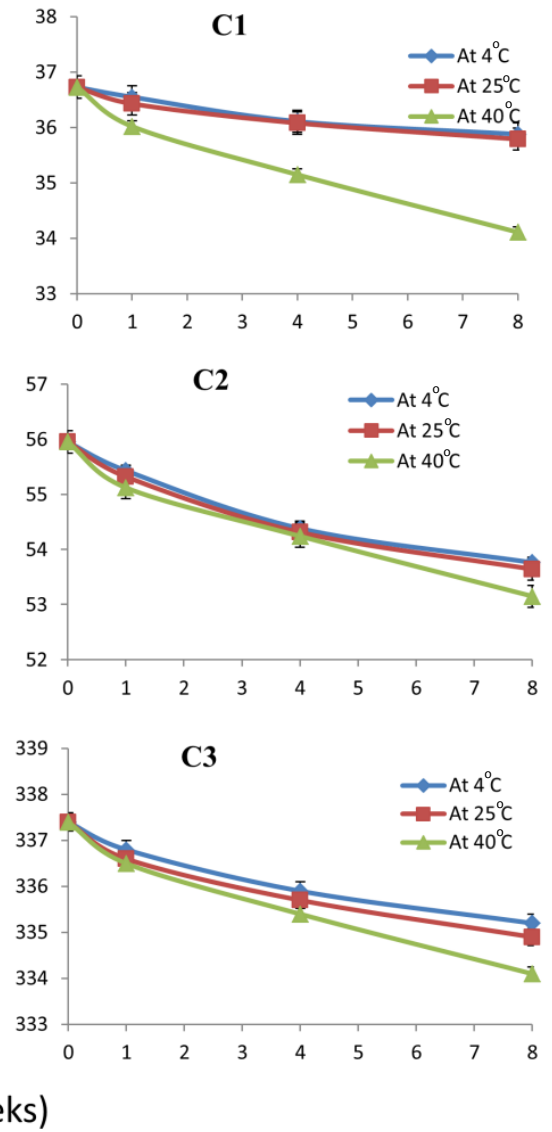

Figure 5. Drug content of microemulsion formulations after 8 week storage at various temperatures. Mean \pm SD, $n=3$.

\subsubsection{Contact Angle Measurements}

Therapeutic activity of the ophthalmic microemulsions depends on the extent to which the fluid wets and covers the corneal surface. Spreading is a fundamental phenomenon in which the fluid phase is displaced completely or partially on the surface of a solid. One of the most useful parameters that is typically used to describe spreading and wetting properties of ophthalmic MEs is the contact angle of the liquid on the hydrophilic corneal surface [38]. The surface of the cornea is typically covered with a hydrophilic mucoid or mucin layer of the tear film to transform the hydrophobic corneal surface into a hydrophilic surface [39]. Therefore, an ophthalmic microemulsion needs to both wet and spread on the corneal surface and then penetrate to maximize the therapeutic activity. The contact angle depends on surface tension of the liquid, surface free energy (interfacial tension between the liquid and the solid) and the interaction forces between the liquid and solid surface and between the liquid molecules themselves. If adhesive forces between the solid surface and the liquid are stronger, the droplet will completely spread out on the solid surface resulting in smaller contact angle. If the cohesive forces within the liquid drop (i.e. hydrogen bonds and Van der Waals forces) are stronger, the droplet will avoid contact with the solid surface resulting in larger contact angle [40]. If the contact angle is low, the fluid will spread to cover or "wet" a larger area of the surface. If the contact angle is high, the fluid will form a compact, self-contained droplet on the surface [41]. The results of contact angle measurements are given in Table 1 . The contact angle of all ME formulations ranged from $12.2^{\circ}$ to $25.2^{\circ}$ on hydrophilic surface and from $25.9^{\circ}$ to $43.8^{\circ}$ on hydrophobic surface. These results indicate that all MEs had relatively low contact angle demonstrating good spreading ability. These results also revealed that all MEs possessed larger contact angle on hydrophobic surface as compared to hydrophilic surface. This could be due to the fact that interfacial tension is high on a hydrophilic 
surface and low on a hydrophobic surface. The high interfacial tension causes low interaction between the hydrophobic solid surface and ME droplet (low surface energy) which results in high contact angle, hence the poor spreading ability.

Overall results indicate that contact angle values for all MEs did not exceeded $90^{\circ}$ on both hydrophilic and hydrophobic surfaces (Table 1), confirming that all MEs have the ability to cover and wet the ocular surface which could potentially translate to increased therapeutic effect.

\subsubsection{Self-Diffusion NMR}

Self-diffusion NMR spectroscopy (DOSY) is a powerful technique for characterisation of microemulsion structures. It is used to distinguish between bicontinuous and droplet type microemulsions [42,43]. It utilizes apparent translational diffusion coefficients in characterizing the microemulsions $[44,45]$. The diffusion coefficients $(D)$ were obtained from the slope of the equation:

$$
\ln \left(\frac{\mathrm{I}_{\mathrm{g}}}{\mathrm{I}_{0}}\right)=-\left[\gamma^{2} g^{2} \delta^{2}\left(\Delta-\frac{\delta}{3}\right)\right] D
$$

The characteristic NMR peaks for fatty acid ( $\alpha$-linolenic acid), surfactants (Tween 80 and Cremophor EL), Transcutol P and water. The proton signal of the terminal methyl group of fatty acid, surfactants and Transcutol P appeared at around 1.02 ppm, 0.95 ppm and 1.25 ppm, respectively, whereas a small peak at approximately 4.7 ppm assigned to water.

The self-diffusion coefficients of fatty acid, surfactants (Tween 80 and Cremophor EL), Transcutol $\mathrm{P}$ and water in ME systems were around $10^{-1} \mathrm{~m}^{2} / \mathrm{s}$ as shown in Figure $6 \mathrm{~A}, \mathrm{~B}$. These low self-diffusion coefficient values indicate that the bicontinuous microemulsions were not likely to have formed. The self-diffusion coefficients of pure components were also calculated as shown in Figure 6A,B. Then the self-diffusion coefficient values of components in all ME samples were compared with that of the pure component to determine the microemulsion type $[42,43]$.

If the ME system is of a droplet-type, the self-diffusion of the components of the internal pseudo-phase is determined by the diffusion of the droplet itself and therefore will be slower than that of the pure components. In a bicontinuous microemulsion, where both oil and water are forming larger domains, the diffusion of both components is high and of the same magnitude as that of the pure components [42,43].

These results indicate that self-diffusion coefficients of fatty acid, surfactants, Transcutol $\mathrm{P}$ and water in the MEs were lower than that of the pure components. These results suggest the formation of droplet type microemulsions as there is no evidence on the presence of a bicontinuous microstructure from the current NMR data. These results also indicate that the self-diffusion coefficient of fatty acid and surfactants further decreased upon increase of water concentration. The self-diffusion coefficient of water was higher than that of $\alpha$-linolenic acid, Tween 80, Cremophor EL and Transcutol P in all systems but a stronger increase in the water self-diffusion coefficient started at samples containing $30 \%$ $w / w$ of water or more. This suggests a possible change from water-in-oil to oil in water at this point. 
A

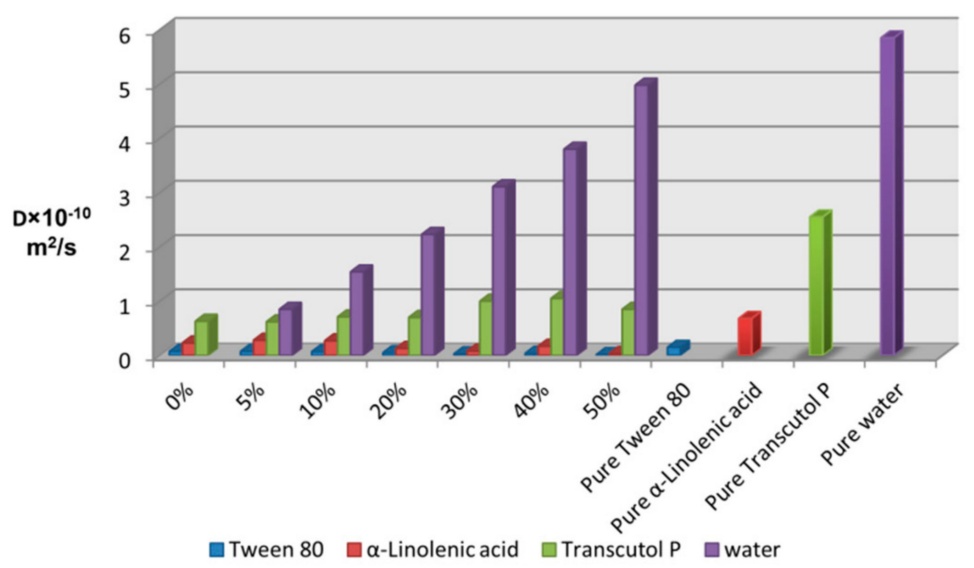

B

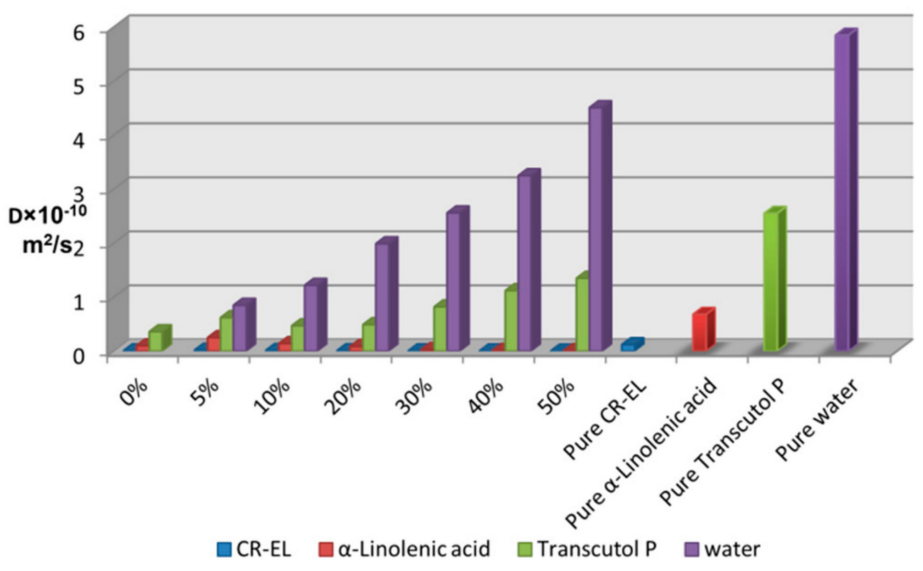

Figure 6. The self-diffusion coefficients of each component in $\alpha$-Linolenic acid/water/Tween 80:Transcutol $\mathrm{P}(1: 1)$ systems containing various concentrations of water from 0 to $50 \%(w / w)(\mathbf{A})$ and each component in $\alpha$-Linolenic acid/water/CR-EL:Transcutol $\mathrm{P}(4: 1)$ systems containing various concentrations of water from 0 to $50 \%(w / w)(\mathbf{B})$.

\subsubsection{Bovine Corneal Opacity and Permeability (BCOP) Test}

The bovine corneal opacity and permeability (BCOP) test measures changes in corneal opacity, determined by changes in light transmission and permeability, measured by increases in permeability to fluorescein, as a result of exposure to a test substance. The opacity and permeability values are used to calculate an in vitro score, in order to reflect the ocular irritation potential [46]. This test is well suited to identify substances moderately and severely irritating to the eye [47]. Figure 7 shows the cumulative bovine eye test scores for the controls and test substances. Apart from Transcutol P and formulation $\mathrm{T} 1$ and $\mathrm{C} 1$, the average cumulative scores calculated for individual components (Tween 80, Cremophor EL and $\alpha$-linolenic acid) and MEs (T2, T3, C2, C3) were found to be less than $0.5(<0.5)$ indicating that they are non-irritating. These test substances did not show any signs of corneal injuries with no changes in corneal opacity, corneal permeability, or epithelial damage]. Transcutol P and ME formulation $\mathrm{T} 1$ and $\mathrm{C} 1$ with an average cumulative score of 1.5, 0.8 and 0.8 , respectively, indicated minor irritation based on corneal opacity and fluorescein permeability. 


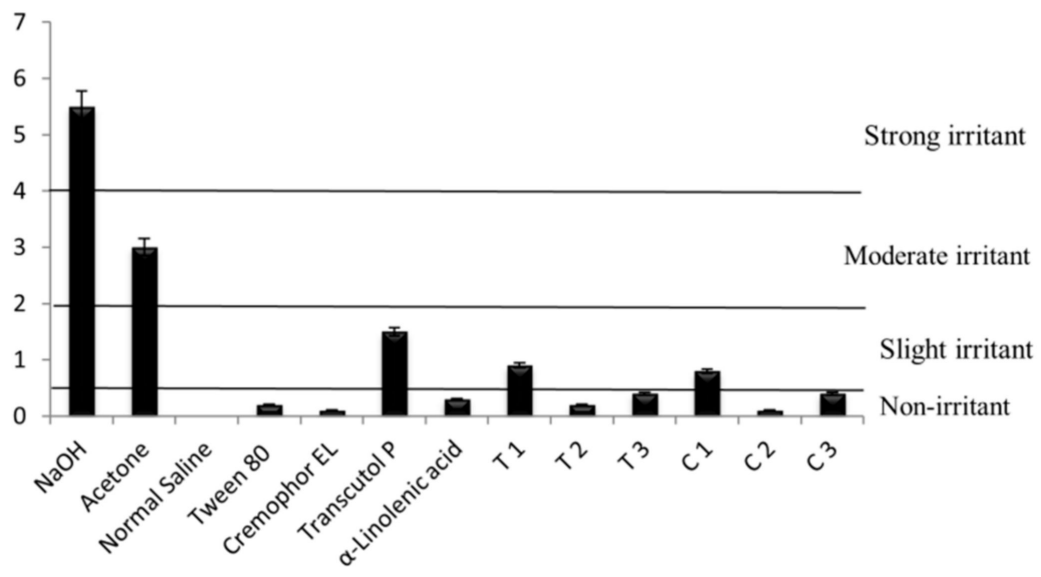

Figure 7. Cumulative BCOP scores of $\mathrm{NaOH}$ (strong positive control), Acetone (moderate positive control), Normal Saline (negative control), Tween 80, Cremophor EL, Transcutol P, and the microemulsion formulations; T1, T2, T3 and C1, C2 and C3. Results are expressed as mean values \pm SD, $n=3$.

The healthy cornea is transparent and completely impermeable to fluorescein dye, due to the exclusive tight junctions of the corneal epithelium. Figure 8 show photographs of corneal opacity and fluorescein permeability for controls and test materials. These results showed that $\mathrm{NaOH}$ induced marked opacity and complete fluorescein staining of cornea whereas saline (negative control) caused no corneal opacity or staining as shown in Figure 8. Transcutol P caused slight irritation manifested as weak corneal opacity and permeability. Two formulations (T1 and C1) also exhibited slight corneal opacity and fluorescein staining which could be due to the high percentage of surfactant:co-surfactant in $\mathrm{T} 1$ and $\mathrm{C} 1$ (88\% and 86\%, respectively). Overall, the tested formulaions did not cause any strong corneal irritation signs and as such were regarded as safe to further test in live animals.

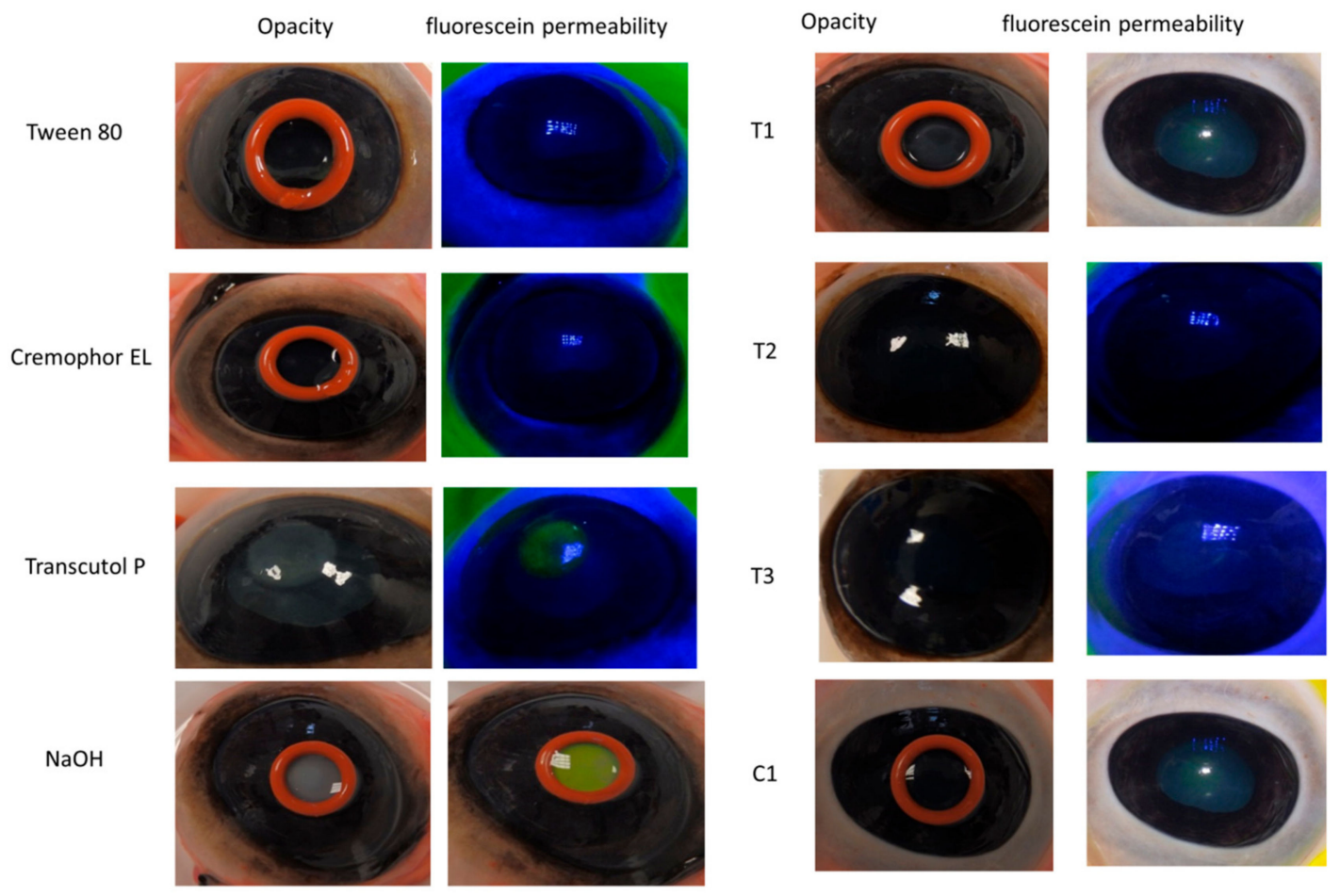

Figure 8. Degree of corneal opacity and fluorescein permeability for Tween 80, Cremophor EL, Transcutol $\mathrm{P}, \mathrm{NaOH}$ and the microemulsion formulations; T1, T2, T3 and C1. 


\subsubsection{Hen's Egg Test Chorioallantoic Membrane (HET-CAM)}

The HET-CAM provides invaluable information on the conjunctival irritation potential of the test substance. The CAM responds to injury with a complete inflammatory process similar to that induced by the conjunctival tissue of the eye [46]. After the treatment, the surface of the CAM was observed for any changes at different time points (after $30 \mathrm{~s}, 1 \mathrm{~min}, 2 \mathrm{~min}$ and $5 \mathrm{~min}$ ) and the average cumulative HET-CAM test scores for the controls and test materials were calculated (Figure 9). The average cumulative scores calculated for individual components (Tween 80, Cremophor EL and $\alpha$-linolenic acid) and MEs $(\mathrm{T} 2, \mathrm{C} 2, \mathrm{C} 3)$ were found to be less than $0.9(<0.9)$. These results reveal that these tested substances are practically non-irritant when applied to the surface of the CAM. In contrast, Transcutol P and three ME formulation (T1, T3 and C1) showed slight irritant effects with an average cumulative score of 4.6, 1.2, 1.4 and 1.1, respectively (Figure 9). The results of the ocular irritation of Transcutol $\mathrm{P}$ are in agreement with the findings of Liu et al. who found that Transcutol P causes slight irritation at a concentration of $0.05 \%$ without any visible ocular damage or abnormal clinical signs involving the cornea, iris, or conjunctivae at all concentrations [48].

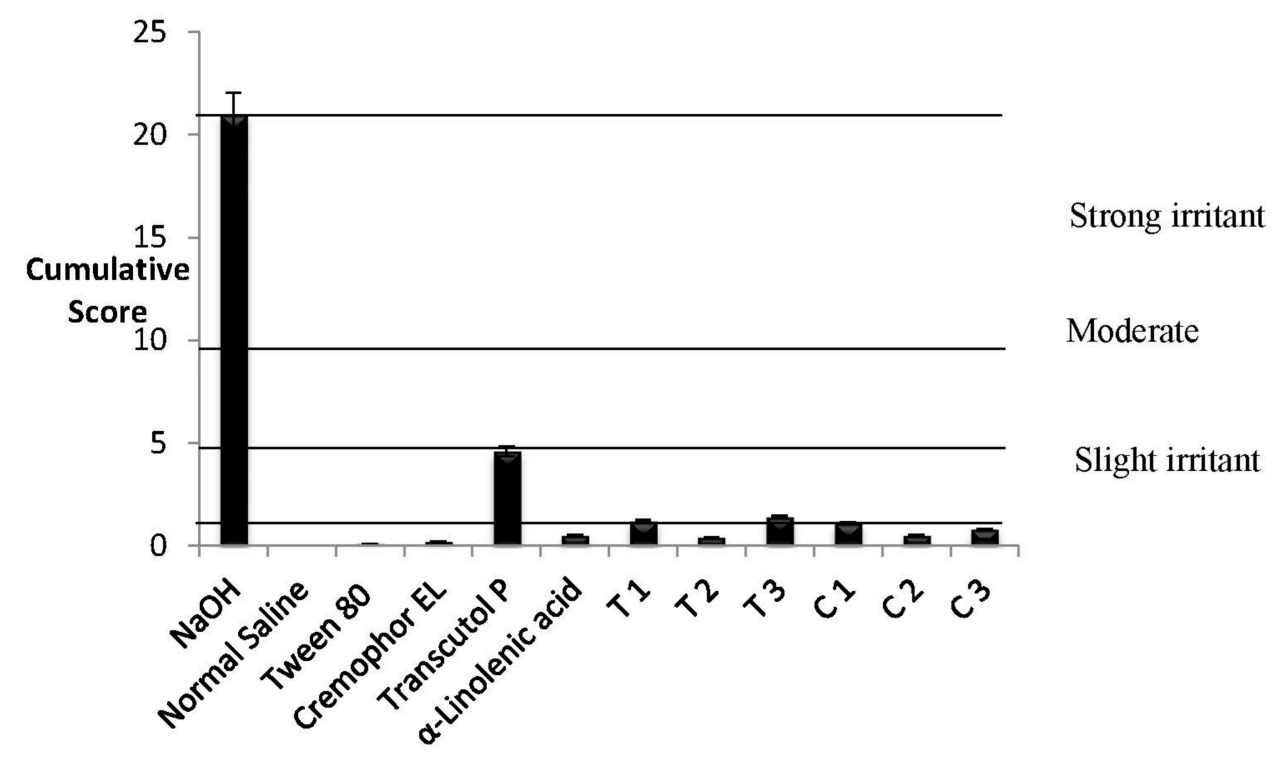

Figure 9. Cumulative HET-CAM scores of $\mathrm{NaOH}$, Acetone, Normal Saline, Tween 80, Cremophor EL, Transcutol P, and the microemulsion formulations; T1, T2, T3 and C1, C2 and C3. Results are expressed as mean values $\pm \mathrm{SD}, n=3$.

Figure 10 shows the effects induced by the tested formulations and the selected controls on the surface of the CAM before and after treatment for 5 min of contact. These results showed that $\mathrm{NaOH}$ (positive control) induced major damage and caused complete lysis and degradation of immature blood vessels when applied to the surface of the CAM (Figure 10A), whereas the normal saline showed no effect (Figure 10B). Transcutol P caused slight degradation of blood vessels (Figure 10C). Three microemulsion formulations (T1, T3 and C1) developed minimal irritation potential manifested as very slight lysis of blood vessels after $5 \mathrm{~min}$ as shown in Figure 10E-G) respectively. Overall, none of the tested formulations caused any major damage to the blood vessels. These results indicate that all of the tested formulations did not show strong irritant effect when applied to the surface of the CAM. 

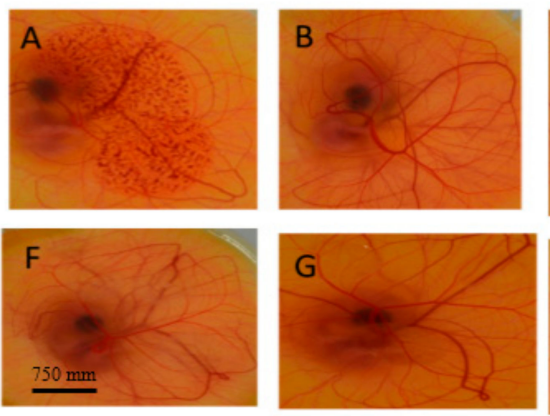
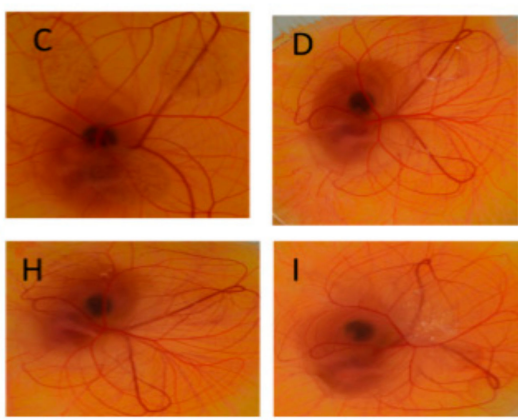
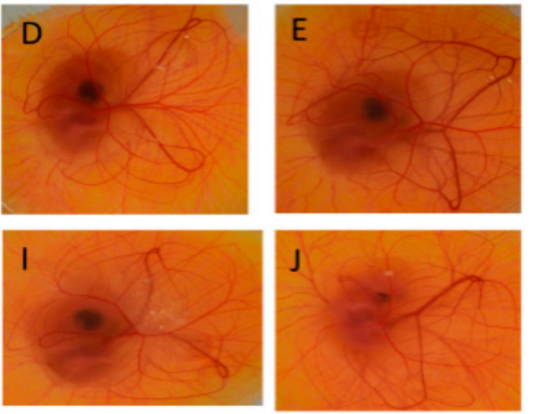

Figure 10. Effect of controls and test substances on the surface of the chorioallantoic membrane (CAM) after treatment for $5 \mathrm{~min}(\mathbf{A}) \mathrm{NaOH},(\mathbf{B})$ Normal saline, (C) Transcutol P, (D) Tween 80, (E) microemulsion (T1), (F) microemulsion (T2), (G) microemulsion (T3), (H) microemulsion (C1), (I) microemulsion (C3), (J) microemulsion (C2).

\subsubsection{Antibacterial Activity of Microemulsions against N. gonorrhoeae and S. aureus}

In this study, the individual components ( $\alpha$-linolenic acid, Tween 80, Cremophor EL and Trascutol P) and six formulated MEs were tested against N. gonorrhoeae and S. aureus (Table 2). The results showed that both N. gonorrhoeae and S. aureus were susceptible to all ME formulations. Fatty acids are known to kill or inhibit the growth of bacteria by disrupting cell membrane which is caused by interference with the electron transport chain and the disruption of oxidative phosphorylation. The electron transport chain is located in the inner membrane of bacterium and is essential source of energy for bacterium. The disruption of electron transport chain is caused either by directly binding of FAs to the electron carriers of the electron transport chain or by insertion into the inner membrane so the ability of the electron transport chain to transfer electrons is impaired. This result in reduced proton gradient and membrane potential which results in reduced ATP production, an essential source of energy for bacterium. FAs may also inhibit the bacterial growth by cell lysis, inhibition of enzyme activity, impairment of nutrient uptake and the generation of toxic peroxidation and autoxidation products [49]. Among the individual components Tween 80, Cremophor EL and Transcutol P exhibited antibacterial activity against only S. aureus. These results also indicate that T3 (35\% $\alpha$-linolenic acid and 60\% surfactant:co-surfactant) and C3 (35\% $\alpha$-linolenic acid and $60 \%$ surfactant:co-surfactant) exhibited the larges antibacterial zones of inhibition against both microbial agents compared to other formulations. T1, T2, C1 and C2 showed medium antibacterial zone against $S$. aureus whereas these MEs showed lowest antibacterial zone against $N$. gonorrhoeae. Overall, all ME formulations showed strong inhibitory effect against $S$. aureus compared to $N$. gonorrhoeae. This might be due to the fact that all excipients (Tween 80, Cremophor EL, Transcutol P) showed strong antimicrobial effect against $S$. aureus compared to $N$. gonorrhoeae.

Table 2. Growth inhibition zone diameter of three selected $\alpha$-linolenic acid based ME formulations and individual components against $N$. gonorrhoeae and $S$. aureus mean $\pm \mathrm{SD} \%(n=3)$.

\begin{tabular}{ccc}
\hline Formulation & Zone of Inhibition against $\boldsymbol{N}$. gonorrhoeae & Zone of Inhibition against $S$. aureus \\
\hline T1 & $6.5 \pm 0.7 \mathrm{~mm}$ & $14.5 \pm 0.7 \mathrm{~mm}$ \\
T2 & $8.5 \pm 0.7 \mathrm{~mm}$ & $15 \pm 1.00 \mathrm{~mm}$ \\
T3 & $22 \pm 1.00 \mathrm{~mm}$ & $21.5 \pm 0.7 \mathrm{~mm}$ \\
C1 & $6.75 \pm 0.4 \mathrm{~mm}$ & $17.75 \pm 0.4 \mathrm{~mm}$ \\
C2 & $8 \pm 1.00 \mathrm{~mm}$ & $16.2 \pm 0.8 \mathrm{~mm}$ \\
C3 & $22.75 \pm 0.4 \mathrm{~mm}$ & $22.25 \pm 1.06 \mathrm{~mm}$ \\
\hline & Active ingredients & \\
Tween 80 & 0.00 & $16.0 \pm 1.4 \mathrm{~mm}$ \\
Cremophor-EL & 0.00 & $7.5 \pm 0.7 \mathrm{~mm}$ \\
Transcutol P & 0.00 & $7.5 \pm 0.6$ \\
\hline -linolenic acid $(1 \mathrm{mM})$ & $10.2 \pm 0.6$ & $\mathrm{~mm}$ \\
\hline
\end{tabular}




\section{Materials and Methods}

\subsection{Materials}

Tween 80, Tween 20, Transcutol P, Cremophor EL, PEG 400 and $\alpha$-linolenic acid were purchased from Sigma (Sigma Aldrich, Dorset, UK). The derivatisation reagent, $\mathrm{BCl}_{3}$-methanol $12 \% w / w(12 \%$ boron trichloride in methanol), n-hexane (HPLC grade, purity, $\geq 99 \%$ ) were also purchased from Sigma (Sigma Aldrich, Dorset, UK). Labrasol, Capryol 90 and Labrafil M2125 were kindly gifted from Gattefosse Company (Bracknell, UK).

\subsection{Microorganisms}

Fresh cultures of N. gonorrhoeae strain NCCP11945 were grown on GC agar (Oxoid, Basingstoke, $\mathrm{UK})$ at $37{ }^{\circ} \mathrm{C}$ in an atmosphere of $5 \% \mathrm{CO}_{2}$ for $24 \mathrm{~h}$. The colonies were removed from the culture plate with a loop and suspended into a $3 \mathrm{~mL} \mathrm{GC} \mathrm{broth} \mathrm{until} \mathrm{cloudy.} \mathrm{The} \mathrm{culture} \mathrm{was} \mathrm{mixed} \mathrm{well} \mathrm{and}$ standard density was adjusted to $10^{7} \mathrm{CFU}$ per $\mathrm{mL}$.

Fresh cultures of $S$. aureus strain NCTC06571 were grown on nutrient agar (Oxoid, Basingstoke, $\mathrm{UK})$ at $37^{\circ} \mathrm{C}$ for $24 \mathrm{~h}$. The colonies were removed from the culture plate with a loop and suspended into a $3 \mathrm{~mL}$ Ringer solution until cloudy. The culture was mixed well and the standard density was adjusted to $0.5 \mathrm{McF}$ arland $\left(1.5 \times 10^{8} \mathrm{CFU}\right.$ per $\left.\mathrm{mL}\right)$.

\subsection{Preformulation Studies}

\subsubsection{Excipient Selection (Surfactants \& Co-Surfactants)}

The selection of suitable excipients is essential in the development of microemulsion. Excipients having maximum solubilizing potential for the fatty acid are selected for the formulation of the $\alpha$-linolenic acid based ME. Selection of excipients was done by reviewing the published literature. Surveying the literature, a range of excipients was checked for use in ophthalmic preparations. Tween 20, Tween 80, Cremophor EL, Capryol 90, Labrasol and Labrafil M2125 were selected as surfactants and Transcutol P and PEG 400 were selected as co-surfactants.

3.3.2. Determination of Saturation Solubility of $\alpha$-Linolenic Acid in Different Surfactants and Co-Surfactants

The solubility of $\alpha$-linolenic acid in various surfactants and co-surfactants was determined using a 96 well plate method reported by Bharate et al. [50]. Stock solutions of fatty acid were prepared in methanol $(1 \mu \mathrm{g} / \mathrm{mL}$ to $1800 \mu \mathrm{g} / \mathrm{mL}) .250 \mu \mathrm{L}$ of each of stock solution was transferred into the 96-well plates and the solvent was evaporated then $250 \mu \mathrm{L}$ of different surfactants and co-surfactants was added into the wells and plates were shaken horizontally at $600 \mathrm{rpm}$ for $5 \mathrm{~h}$ at room temperature. The plates were then centrifuged at $3000 \mathrm{rpm}$ for $15 \mathrm{~min}$ and then samples were analysed by UV spectrophotometer at $350 \mathrm{~nm}$. Each experiment was performed in triplicate. The solubility of $\alpha$-linolenic acid was also determined in different ratios of surfactant and co-surfactant as 1:1, 1:4 and 4:1 using 96 well plate method reported above.

\subsubsection{Selection of Surfactant \& Co-Surfactant Blend}

Based on the individual solubility studies, Tween 80 and Cremophor EL were selected as surfactants and Transcutol P was selected as co-surfactant. The solubility of $\alpha$-linolenic acid was also determined in various surfactants and co-surfactants mixtures. The individual non-ionic hydrophilic surfactant was blended with the selected co-surfactant in ratios of 1:1, 1:4 and 4:1 (w/w).

\subsubsection{Construction of Pseudo-Ternary Phase Diagram}

The pseudo-ternary phase diagrams were constructed to determine the concentration range of all components ( $\alpha$-linolenic acid/surfactant/co-surfactant/water) in which they form a microemulsion. 
The surfactant and co-surfactant were mixed at 1:1 and 4:1 ratio. Different mixtures of $\alpha$-linolenic acid and surfactant/co-surfactant mixtures were prepared at weight ratios of 0:10, 0.5:9.5, 1:9, 2:8, 3:7, 4:6, 5:5, 6:4, 7:3, 8:2 and 9:1, respectively. The pseudo-ternary phase diagrams were constructed by using the phase diagram by micro-plate dilution (PDMPD) method, a novel technique based on the water titration method [51]. The microtitre plates were filled by pipette in accordance with the filling scheme: The wells A1 to D5 were filled in two steps. Fatty acids/surfactants/co-surfactants mixture was filled into the wells with $200 \mu \mathrm{L}$ at the first well and down by increments of $5 \mu \mathrm{L}$ to reach $0 \mu \mathrm{L}$. Then, water was added to each well to make a final volume of $200 \mu \mathrm{L}$. After the plates had been filled, they were sealed and then shaken for $24 \mathrm{~h}$ at room temperature $\left(25^{\circ} \mathrm{C}\right)$. After that, the microplates were characterised by measuring absorbance using microplate reader at $600 \mathrm{~nm}$ and by making a visual evaluation of the isotropy and the border between the homogeneous or the heterogeneous system.

The percentage of transmittance of the microemulsion formulations was determined using the following formula, where $\mathrm{T}$ is transmittance and $\mathrm{A}$ is absorbance.

$$
\% \mathrm{~T}=\operatorname{antilog}(\mathrm{A}-2)
$$

\subsubsection{Preparation of Microemulsion Formulations}

According to microemulsion region in the phase diagram, ME formulations were selected at different component ratios. $\alpha$-linolenic acid (ALA) was used as an oil phase. Tween 80 and Cremophor EL were selected as surfactants. Transcutol P was selected as co-surfactant with water as aqueous phase. Surfactant and co-surfactant were mixed at different mass ratios (1:1,4:1). $\alpha$-linolenic acid was dissolved under stirring in mixture of S/CoS. Then, the appropriate amount of water was added to the mixture drop by drop with continuous stirring.

\subsubsection{Characterization of Microemulsions}

Visual Evaluation

Microemulsions were first monitored for transparency, signs of phase separation and birefringence with the aid of visual evaluation. Visual evaluation helps to differentiate between microemulsions and other two phase systems such as emulsions. Visually microemulsions are transparent or translucent, whereas emulsions are turbid.

After visual inspection, the formulations which have better clarity and no phase separation were confirmed for selection as clarity of the formulation is the initial priority of the microemulsion [52].

\section{Polarized Light Microscopy}

Plane polarized light microscopy was used to distinguish between pure microemulsions and microemulsions containing lamellar liquid crystals. ME samples were prepared by placing a drop of ME between a coverslip and a glass slide and were then examined using cross-polarized light microscopy (Polarizing Microscope RPL-55 Series, Radical Instruments, Ambala Cantt, India). The isotropic and anisotropic behaviour of the samples was observed. Isotropic materials such as microemulsion, in contrast to anisotropic liquid crystals, do not interfere with the polarized light and the field of view remains dark because the analyser absorbs light passing through the polarizer.

Droplet Size and Zeta Potential Measurement

The droplet size, polydispersity index (PDI) and zeta potential (ZP) of MEs were measured by dynamic light scattering using a Zetasizer (Malvern instruments Ltd., Malvern, UK). ME samples were analysed in triplicate at $25^{\circ} \mathrm{C}$. 
Determination of $\mathrm{pH}$

The $\mathrm{pH}$ values for microemulsions were determined at $25^{\circ} \mathrm{C}$ by $\mathrm{pH}$ meter (JENWAY model 3305, JENWAY Ltd., Stone, UK). All measurements were carried out in triplicate.

Viscosity Measurements

Viscosity of samples was measured at $25{ }^{\circ} \mathrm{C}$ with a Brookfield viscometer (DV-II+Pro Brookfield., Middleboro, MA 02346, USA) using spindle No. 34. With shear rate $50 \mathrm{rpm}$. Each measurement was performed in triplicate.

\section{Drug Content Determination}

Concentration and drug content of FA-based ME formulations were determined using the Gas Chromatography-Flame Ionization Detector (GC-FID) method [17]. ME samples were derivatised by using $\mathrm{BCl}_{3}$-methanol $(12 \% \mathrm{w} / \mathrm{w})$ in a water bath at $60^{\circ} \mathrm{C}$ for $8 \mathrm{~min}$. Then, samples were extracted with $\mathrm{n}$-hexane (1-2 $\mathrm{mL}$ ) by hand-shaking for $1 \mathrm{~min}$ until both layers were clear. The layers were allowed to settle and the upper (organic) layer was transferred into a clean vial. The organic layer containing fatty acid methyl esters (FAMEs) was dried by adding $500 \mathrm{mg}$ of anhydrous sodium sulphate. Then, samples were analysed by the GC-FID method [17].

\section{Contact Angle Measurements}

Contact angles of prepared microemulsions were measured with goniometer method [40]. A $5 \mu \mathrm{L}$ droplet of the microemulsion was placed on the surface of a plate and the image was immediately sent via the CCD camera to the computer for analysis. Contact angles were determined as the cosine $(\theta)$ of the contact angle $(\theta)$ between the ME droplet attached to the hydrophilic surface (dry glass slide) or hydrophobic surface (glass slide covered with parafilm) and the droplet. For all tests, the mean value of at least three replicate evaluations was reported.

\subsubsection{Stability Studies}

Physical and chemical stability testing of selected microemulsions were performed under the accelerated conditions in triplicate $(n=3)$ to find out the stable microemulsions. For stability testing, microemulsions were kept at various temperatures $\left(4^{\circ} \mathrm{C}, 25^{\circ} \mathrm{C}\right.$ and $\left.40{ }^{\circ} \mathrm{C}\right)$ for 8 weeks. The clarity, phase separation, particle size, zeta potential and drug content of tested microemulsions were determined at 0,1 week, 4 weeks and 8 weeks [53].

\subsubsection{Self-Diffusion NMR}

Self-diffusion NMR measurements were carried out at $600 \mathrm{MHz}$ using a Bruker Avance DRX 600 (Billerica, MA, USA) at $25^{\circ} \mathrm{C}$. Each sample was dissolved in $\mathrm{D}_{2} \mathrm{O}$ (internal standard) and filled into NMR tube. The self-diffusion coefficients of pure components were calculated. The self-diffusion coefficients of components in the microemulsion samples were compared with those of the single components to determine the type of microemulsion. The diffusion coefficients $(D)$ were obtained from the slope of the Stejskal-Tanner equation [54]:

$$
\ln \left(\frac{\mathbf{I}_{\mathbf{g}}}{\mathbf{I}_{\mathbf{0}}}\right)=-\left[\gamma^{2} g^{2} \delta^{2}\left(\Delta-\frac{\delta}{3}\right)\right] D
$$

where $\mathbf{I}_{\mathbf{g}}$ and $\mathbf{I}_{\mathbf{0}}$ are intensities of the NMR signal in the presence and absence of field gradient pulses; $\gamma$ is the gyromagnetic constant for $1 \mathrm{H} ; g$ is the duration of the z-gradient pulse; $\delta$ is the gradient strength; and $\Delta$ is the time interval between the gradient pulses. 


\subsubsection{Antibacterial Activity of MEs against N. gonorrhoea and S. aureus}

The antimicrobial activity of prepared microemulsions and its individual components against $N$. gonorrhoea and S. aureus were checked using disc diffusion method $[17,18]$. Blank paper discs $(6 \mathrm{~mm}$ diameter) were loaded with $10 \mu \mathrm{L}$ of the microemulsion formulations and its individual components and allowed to air-dry at room temperature. Nutrient agar plates were inoculated with bacterial suspension by dipping a sterile cotton wool swab into the suspension and spreading the inoculum evenly over the entire surface of the plates by swabbing in three directions. Plates were allowed to dry before applying discs. Then, the discs containing the test agents were applied to the surfaces of inoculated plates. Plates were inverted and incubated at $37^{\circ} \mathrm{C}$ for $24 \mathrm{~h}$ to allow for bacterial growth. Inhibition zone diameters were measured in millimetres. All measurements were carried out in triplicate.

\subsubsection{Ocular Irritation Testing}

In this study, BCOP \& HET-CAM tests were used to investigate the ocular irritation potential of prepared microemulsions and their ingredients.

\section{BCOP Test}

Bovine's eyes acquisition and examination. Bovine eyes were obtained from a local slaughter house. The eyes were examined for epithelium detachment, corneal opacity and corneal vascularization. Eyes with corneal damage or abnormalities were discarded.

Test substances. $\mathrm{NaOH}(0.5 \mathrm{M})$ was used as a positive control strong irritant, acetone as a moderate irritant and normal saline as a negative control [46]. Microemulsions and all used ingredients ( $\alpha$-linolenic acid, Tween 80, Cremophor EL and Transcutol P) were investigated for their corneal irritation potential using BCOP test.

Irritation testing, scoring and classification. The eyes were held with small plastic cups (cornea upwards) in the humid atmosphere of a closed water bath at $37^{\circ} \mathrm{C}+0.5^{\circ} \mathrm{C}$ for $10 \mathrm{~min}$. A silicon O-ring was carefully placed on the central part of the cornea. One drop of saline was applied inside the ring and eyes were equilibrated in a closed water bath for $5 \mathrm{~min}$. Then the test substance was applied to the cornea inside the ring at a volume of $0.1 \mathrm{~mL}$. After $30 \mathrm{~s}$, the eyes were rinsed with approximately $10 \mathrm{~mL}$ saline and further incubated in the closed water bath for $10 \mathrm{~min}$. The extent of corneal injury was assessed by evaluating the opacity. Then sodium fluorescein solution $(2 \% w / v$ and $\mathrm{pH} 7.4)$ was applied to the cornea and corneal permeability was assessed using examination lamp and cobalt blue filter and following the scoring systems [46] in Table 3.

Table 3. Bovine eye scoring system.

\begin{tabular}{cccccc}
\hline Opacity & Score & Fluorescein Permeability & Score & Cumulative Score & Interpretation \\
\hline None & 0 & None & 0 & $\leq 0.5$ & None \\
Slight & 1 & Diffuse and weak & 0.5 & $0.6-1.9$ & Slight \\
Marked & 2 & Confluent and weak & 1 & $2.0-4.0$ & Moderate \\
Severe & 3 & Confluent and intense & 1.5 & $>4$ & Severe \\
Opaque & 4 & - & - & - & - \\
\hline
\end{tabular}

\section{HET-CAM Test}

Preparation of the CAMs. CAMs were prepared following the protocol early described by Reference [18]. Briefly, freshly collected fertilised hen's eggs were incubated at $37.5{ }^{\circ} \mathrm{C} \pm 0.5^{\circ} \mathrm{C}$ and $66 \% \pm 5 \%$ relative humidity $(\mathrm{RH})$ for 3 days. During incubation, eggs were turned by hand five times per day to prevent the attachment of the embryo to one side of the egg. On day three, the eggshells were opened by cracking the underside of the egg against the edge of a plastic Petri dish. The content of the shell was then poured into a growing chamber. The growing chamber was made of a glass 
beaker over which a piece of cellophane membrane was attached and fixed in position using a circular plastic sleeve. Once in the growing chamber, each egg was examined for the viability of the embryo (intact CAM and yolk sac). Defective or non-viable eggs were discarded and only viable embryos with intact CAMs and yolk sacs were further incubated $[46,55]$.

$\mathrm{NaOH}(0.1 \mathrm{M})$ was used as a positive control strong irritant and normal saline as a negative control. All prepared microemulsions and excipients; (Tween 80, Transcutol P, PEG 400, $\alpha$-linolenic acid) were tested for their ocular irritation potential.

Irritation testing, scoring and classification. On day 10, $0.2 \mathrm{~mL}$ of the test substances was placed onto the CAM. For each test substance three eggs were used. After treatment with test substances, the blood vessels and capillaries were examined for the irritant effects of hyperaemia, haemorrhage, clotting and/or coagulation at different times post application [25,26]. A time dependent numerical score was then allocated to each test compound or formulation. The sum of the time dependent numerical scores for all three responses of hyperaemia, haemorrhage, clotting and/or coagulation gives a single numerical value (Table 4 ). The mean value of four tests allows for the assessment by a classification scheme similar to the Draize test [56].

Table 4. Irritation scores and interpretations used in HET-CAM test.

\begin{tabular}{cccccc}
\hline & \multicolumn{3}{c}{ Score } & Cumulative Score & Irritation Assessment \\
\hline Effect & $0.5 \min$ & $2 \mathrm{~min}$ & $5 \mathrm{~min}$ & $0-0.9$ & None \\
Hyperaemia & 5 & 3 & 1 & $1.0-4.9$ & Slight \\
Haemorrhage & 7 & 5 & 3 & $5.0-8.9$ & Moderate \\
Coagulation & 9 & 7 & 5 & $9.0-21.0$ & Severe \\
\hline
\end{tabular}

\subsubsection{Statistical Analysis}

All the experiments were repeated three times and data were expressed as the mean value \pm SD. Statistical analysis was performed using the software Graphpad Prism (Graphpad Prism software, Inc., San Diego, CA, USA). Statistical data were analysed by one-way analysis of variance (ANOVA) and Student's t test. Differences were considered significant for $p<0.05$.

\section{Conclusions}

In this study, fatty acid based microemulsions were prepared and evaluated. The selection of surfactant and cosurfactants were selected after evaluating the saturation solubility of lineolenic acid in different systems while Pseudo-ternary phase diagrams were constructed to evaluate the regions of microemulsion. Nine different fatty acid-based microemulsions were prepared comprising of $\alpha$-linolenic acid as oil phase, Tween 80 and Cremophor EL as surfactant, Transcutol P as co-surfactant and water as aqueous phase. The prepared microemulsions were characterized, showing an average particle size around $250 \mathrm{~nm}$ and a $\mathrm{pH}$ of 5.5. The prepared ME formulations were isotropic colloidal dispersions and did not show any lamellar and hexagonal liquid crystals when examined using polarized light microscopy.

All ME formulations were stable upon storage for 8 weeks without significant change in particle size and drug content as it is believed that the ME formulations protected the $\alpha$-linolenic acid from autoxidation. All MEs exerted strong antimicrobial effects against $N$. gonorrhoeae and S. aureus without being irritant to the eye as suggested by the BCOP and HET-CAM studies. The study suggests that $\alpha$-linolenic acid ME can be used as an effective and stable therapy for treatment of ophthalmia neonatorum conditions caused by Neisseria gonorrhoeae and Staphylococcus aureus.

Author Contributions: Raid G. Alany, Lori A. S. Snyder, Adam Le Gresley, Ali A. Alkinani and Amr ElShaer conceived and designed the experiments; Ummara Butt and Ali A. Al-kinani performed the experiments; Ummara Butt analysed the data; Ali Alkinani, Adam Le Gresley and Lori Snyder contributed reagents/materials/analysis tools; Ummara Butt and Amr ElShaer wrote the paper. 
Conflicts of Interest: The authors declare no conflict of interest.

\section{References}

1. Di Bartolomeo, S.; Mirta, D.H.; Janer, M.; Rodriguez, M.R.; Sauka, D.; Magarinos, F.; De Torres, R.A. Incidence of Chlamydia trachomatis and other potential pathogens in neonatal conjunctivitis. Int. J. Infect. 2001, 5, 139-143. [CrossRef]

2. Kellogg, D.S., Jr.; Peacock, W.L., Jr.; Deacon, W.E.; Brown, L.; Pirkle, D.I. Neisseria Gonorrhoeae. I. Virulence Genetically Linked to Clonal Variation. J. Bacteriol. 1963, 85, 1274-1279. [PubMed]

3. Matejcek, A.; Goldman, R.D. Treatment and prevention of ophthalmia neonatorum. Can. Fam. Physician 2013, 59, 1187-1190. [PubMed]

4. Palafox, S.K.V.; Jasper, S.; Allyson, D.; Foster, S.C. Ophthalmia Neonatorum. J. Clin. Exp. Ophthalmol. $2011,2,119$. [CrossRef]

5. Laga, M.; Meheus, A.; Piot, P. Epidemiology and control of Gonococcal ophthalmia neonatorum. Bull. World Health Organ. 1989, 67, 471-477. [PubMed]

6. Laga, M.; Plummer, F.A.; Piot, P.; Datta, P.; Namaara, W.; Ndinya-Achola, J.O.; Nzanze, H.; Maitha, G.; Ronald, R.A.; Pamba, O.H. Prophylaxis of Gonococcal and chlamydial ophthalmia neonatorum. A comparison of silver nitrate and tetracycline. N. Engl. J. Med. 1988, 318, 653-657. [CrossRef] [PubMed]

7. Nishida, H.; Resenberg, H.M. Silver nitrate ophthalmic solution and chemical conjunctivitis. Pediatrics 1975, 56, 368-373. [PubMed]

8. Bergsson, G.; Steingrimsson, O.; Thormar, H. In vitro susceptibilities of Neisseria Gonorrhoeae to fatty acids and monoglycerides. Antimicrob. Agents Chemother. 1999, 43, 2790-2792. [PubMed]

9. Lepage, P.; Bogaerts, J.; Kestelyn, P.; Meheus, A. Single-dose cefotaxime intramuscularly cures gonococcal ophthalmia neonatorum. Br. J. Ophthalmol. 1988, 72, 518-520. [CrossRef] [PubMed]

10. Ohnishi, M.; Saika, T.; Hoshina, S.; Iwasaku, K.; Nakayama, S.; Watanabe, H.; Kitawaki, J. Ceftriaxone-resistant Neisseria Gonorrhoeae, Japan. Emerg. Infect. Dis. 2011, 17, 148-149. [CrossRef] [PubMed]

11. Ohnishi, M.; Golparian, D.; Shimuta, K.; Saika, T.; Hoshina, S.; Iwasaku, K.; Nakayama, S.; Kitawaki, J.; Unemo, M. Is Neisseria Gonorrhoeae initiating a future era of untreatable Gonorrhoea? Detailed characterization of the first strain with high-level resistance to ceftriaxone. Antimicrob. Agents Chemother. 2011, 55, 3538-3545. [CrossRef] [PubMed]

12. Bergsson, G.; Arnfinnsson, J.; Steingrimsson, O.; Thormar, H. In Vitro Killing of Candida albicans by Fatty Acids and Monoglycerides. Antimicrob. Agents Chemother. 2001, 45, 3209-3212. [CrossRef] [PubMed]

13. Sun, C.Q.; O'Connor, C.J.; Roberton, A.M. Antibacterial actions of fatty acids and monoglycerides against Helicobacter pylori. FEMS Immunol. Med. Microbiol. 2003, 36, 9-17. [CrossRef]

14. Miller, R.D.; Brown, K.E.; Morse, S.A. Inhibitory action of Fatty acids on the growth of Neisseria Gonorrhoeae. Infect. Immun. 1977, 17, 303-312. [PubMed]

15. Desbois, A.P.; Lawlor, K.C. Antibacterial Activity of Long-Chain Polyunsaturated Fatty Acids against Propionibacterium acnes and Staphylococcus aureus. Mar. Drugs 2013, 11, 4544-4557. [CrossRef] [PubMed]

16. Thormar, H.; Bergsson, G.; Gunnarsson, E.; Georgsson, G.; Witvrouw, M.; Steingrimsson, O.; De Clercq, E.; Kristmundsdottir, T. Hydrogels containing monocaprin have potent microbicidal activities against sexually transmitted viruses and bacteria in vitro. Sex. Transm. Infect. 1999, 75, 181-185. [CrossRef] [PubMed]

17. Butt, U.; ElShaer, A.; Snyder, L.A.; Chaidemenou, A.; Alany, R.G. Fatty acid microemulsion for the treatment of neonatal conjunctivitis: Quantification, characterisation and evaluation of antimicrobial activity. Drug Deliv. Transl. Res. 2016, 6, 722-734. [CrossRef] [PubMed]

18. Snyder, L.; Churchward, C.; Alany, R.; Kirk, R.S.; Walker, T. Prevention of ophthalmia neonatorum from 'Neisseria gonorrhoea' using a fatty acid-based formulation. mBio 2017, 8. [CrossRef]

19. Keenan, J.; Eckert, S.; Rutar, T. Cost analysis of povidone-iodine for ophthalmia neonatorum prophylaxis. Arch. Ophthalmol. 2010, 128, 136-137. [PubMed]

20. Patel, K.; Sarma, V.; Vavia, P. Design and evaluation of Lumefantrine-Oleic acid self-nanoemulsifying ionic complex for enhanced dissolution. DARU J. Pharm. Sci. 2013, 21, 1-10. [CrossRef] [PubMed]

21. Mosca, M.; Cuomo, F.; Lopez, F.; Ceglie, A. Role of emulsifier layer, antioxidants and radical initiators in the oxidation of olive oil-in-water emulsions. Food Res. Int. 2013, 50, 377-383. [CrossRef] 
22. Narang, A.S.; Delmarre, D.; Gao, D. Stable drug encapsulation in micelles and microemulsions. Int. J. Pharm. 2007, 345, 9-25. [CrossRef] [PubMed]

23. Junyaprasert, V.B.; Boonme, P.; Wurster, D.E.; Rades, T. Aerosol OT microemulsions as carriers for transdermal delivery of hydrophobic and hydrophilic local anesthetics. Drug Deliv. 2008, 15, 323-330. [CrossRef] [PubMed]

24. El Maghraby, G.M. Transdermal delivery of hydrocortisone from eucalyptus oil microemulsion: Effects of cosurfactants. Int. J. Pharm. 2008, 355, 285-292. [CrossRef] [PubMed]

25. Djekic, L.; Primorac, M.; Jockovic, J. Phase behaviour, microstructure and ibuprofen solubilization capacity of pseudo-ternary non-ionic microemulsions. J. Mol. Liq. 2011, 160, 81-87. [CrossRef]

26. Tarr, B.D.; Yalkowsky, S.H. Enhanced intestinal absorption of cyclosporin in rats through the reduction of emulsion droplet size. Pharm. Res. 1989, 6, 40-43. [CrossRef] [PubMed]

27. Liu, L.; Pang, X.; Zhang, W.; Wang, S. Silymarin-loaded self microemulsifying drug delivery systems. Asian J. Pharm. Sci. 2007, 2, 150-160.

28. James-Smith, M.A.; Alford, K.; Shah, D.O. A novel method to quantify the amount of surfactant at the oil/water interface and to determine total interfacial area of emulsions. J. Colloid Interface Sci. 2007, 310, 590-598. [CrossRef] [PubMed]

29. Patist, A.; Chhabra, V.; Pagidipati, R.; Shah, R.; Shah, D.O. Effect of chain length compatibility on micellar stability in sodium dodecyl sulfate/alkyltrimethylammonium bromide solutions. Langmuir 1997, 13, 432-434. [CrossRef]

30. Adhikary, T.P.; Chowdhury, P.; Chakravorti, S. Modulation of photophysics of 2-hydroxy-1-naphthaldehyde in non-ionic micelles. Chem. Phys. Lett. 2007, 442, 504-510. [CrossRef]

31. Patel, R.B.; Patel, M.R.; Parikh, J.R.; Solanki, A.B.; Patel, B.G. Effect of formulation components on the in vitro permeation of microemulsion drug delivery system of fluconazole. AAPS Pharm. Sci. Tech. 2009, 10, 917-923. [CrossRef] [PubMed]

32. Gupta, S.; Kesarla, R.; Omri, A. Formulation Strategies to Improve the Bioavailability of Poorly Absorbed Drugs with Special Emphasis on Self-Emulsifying Systems. ISRN Pharm. 2013, 2013, 1-16. [CrossRef] [PubMed]

33. Yadav, P.S.; Yadav, E.; Verma, A.; Amin, S. Development, Characterization and Pharmacodynamic Evaluation of Hydrochlorothiazide Loaded Self-Nanoemulsifying Drug Delivery Systems. Sci. World J. 2014, 2014, 1-10. [CrossRef] [PubMed]

34. Niculae, G.; Lǎcǎtuşu, I.; Badea, N.; Opera, O.; Meghea, A. Optimization of lipid nanoparticles composition for sunscreen encapsulation. U.P.B. Sci. Bull. Ser. B. 2013, 75, 79-92.

35. Gupta, S.; Bansal, B.; Ali, J.; Gabrani, R.; Dang, S. Development and Characterization of Polyphenon 60 and Caffeine Microemulsion for Enhanced Antibacterial Activity. BioMed Res. Int. 2014, 2014, 1-7. [CrossRef] [PubMed]

36. Choe, E.; Min, D. Mechanisms and Factors for Edible Oil Oxidation. Compr. Rev. Food Sci. Food Saf. 2006, 5, 169-186. [CrossRef]

37. Allen, R.R.; Jackson, A.; Kummerow, F.A. Factors which affect the stability of highly unsaturated fatty acids. I. Differences in the oxidation of conjugated and nonconjugated linoleic acid. J. Am. Oil Chem. Soc. 1949, 26, 395-399. [CrossRef]

38. Wang, W.; Wei, H.; Du, Z.; Tai, X.; Wang, G. Formation and Characterization of fully dilutable microemulsion with fatty acid methyl esters as oil phase. ACS Sustain. Chem. Eng. 2015, 3, 443-450. [CrossRef]

39. Montgomery, T.M. Anatomy, Physiology \& Pathology of the Human Eye: The Cornea. Available online: http:/ / www.tedmontgomery.com/the_eye/cornea.html (accessed on 25 July 2017).

40. Yuan, Y.; Lee, T.R. Contact Angle and Wetting Properties: Surface Science Techniques; Springer Series in Surface Sciences; Springer: Berlin/Heidelberg, Germany, 1998; Volume 51, pp. 3-34.

41. Kwok, D.Y.; Neumann, A.W. Contact angle techniques and measurements. In Surface Characterization Methods: Principles, Techniques and Applications; Milling, A.J., Ed.; Marcel Dekker: New York, NY, USA, 1999; p. 37.

42. Boonme, P.; Krauel, K.; Graf, A.; Rades, T.; Junyaprasert, V.B. Characterisation of microstructures formed in isopropyl palmitate/water/Aerosol OT: 1-butanol (2:1) system. Pharmazie 2006, 61, 927-932. [PubMed]

43. Boonme, P.; Krauel, K.; Graf, A.; Rades, T.; Junyaprasert, V.B. Characterization of Microemulsion Structures in the Pseudoternary Phase Diagram of Isopropyl Palmitate/Water/Brij 97:1 Butanol. AAPS Pharm. Sci. Tech. 2006, 7, E1-E6. [CrossRef] [PubMed] 
44. Liu, H.; Wang, Y.; Lang, Y.; Yao, H.; Dong, Y.; Li, S. Bicontinuous cyclosporin a loaded water-AOT/Tween 85-isopropylmyristate microemulsion: Structural characterization and dermal pharmacokinetics in vivo. J. Pharm. Sci. 2009, 98, 1167-1176. [CrossRef] [PubMed]

45. Hathout, R.M.; Woodman, T.J. Applications of NMR in the characterization of pharmaceutical microemulsions. J. Control Release 2012, 161, 62-72. [CrossRef] [PubMed]

46. Abdelkader, H.; Ismail, S.; Hussein, A.; Wua, Z.; Al-Kassasa, R.; Alany, R.G. Conjunctival and corneal tolerability assessment of ocular naltrexone noisome and their ingredients on the hen's egg chorioallantoic membrane and excised bovine cornea models. Int. J. Pharm. 2012, 432, 1-10. [CrossRef] [PubMed]

47. Shafaie, S.; Hutter, V.; Cook, M.T.; Brown, M.B.; Chau, D.Y.S. In Vitro Cell Models for Ophthalmic Drug Development Applications. Biores. Open Access 2016, 5, 94-108. [CrossRef] [PubMed]

48. Liu, Z.; Li, J.; Nie, S.; Guo, H.; Pan, W. Effects of Transcutol P on the corneal permeability of drugs and evaluation of its ocular irritation of rabbit eyes. J. Pharm. Pharmacol. 2006, 58, 45-50. [CrossRef] [PubMed]

49. Desbois, A.P.; Valerie, J.S. Antibacterial free fatty acids: Activities Mechanism of action and Biotechnological potential. Appl. Microbiol. Biotechnol. 2010, 85, 1629-1642. [CrossRef] [PubMed]

50. Bharate, S.S.; Vishwakarma, R.A. Thermodynamic equilibrium solubility measurements in simulated fluids by 96-well plate method in early drug discovery. Bioorg. Med. Chem. Lett. 2015, 25, 1561-1567. [CrossRef] [PubMed]

51. Schmidts, T.; Nocker, P.; Lavi, G.; Kuhlmann, J.; Czermak, P.; Runkel, F. Development of an alternative, time and cost saving method of creating pseudoternary diagrams using the example of a microemulsion. Colloids Surf. A Physicochem. Eng. Asp. 2009, 340, 187-192. [CrossRef]

52. Patel, R.B.; Patel, M.R.; Bhatt, K.K.; Patel, B.G. Formulation and evaluation of Microemulsion based Drug Delivery system for intra nasal administration of Olanzapine. Int. J. Biomed. Pharm. Sci. 2012, 7, 20-27.

53. European Medicines Agency. Stability Testing on New Drug Substances and Products. In Proceedings of the International Conference on Harmonization Guidance for Industry Q1A (R2); Geneva International Federation of Pharmaceutical Manufacturers \& Associations: Geneva, Switzerland, 2000.

54. Stejskal, E.O.; Tanner, J.E. Spin diffusion measurements: Spin echoes in the presence of a time dependent field gradient. J. Chem. Phys. 1965, 42, 288-292. [CrossRef]

55. Alany, R.G.; Rades, T.; Nicoll, J.; Tucker, I.G.; Davies, N.M. W/O microemulsions for ocular delivery: Evaluation of ocular irritation and precorneal retention. J. Control. Release 2006, 111, 145-152. [CrossRef] [PubMed]

56. Luepke, N.P. Hen's egg chorioallantoic membrane test for irritation potential. Food Chem. Toxicol. 1985, 23, 287-291. [CrossRef]

(C) 2018 by the authors. Licensee MDPI, Basel, Switzerland. This article is an open access article distributed under the terms and conditions of the Creative Commons Attribution (CC BY) license (http://creativecommons.org/licenses/by/4.0/). 